\title{
ANATOMIA DAS MADEIRAS DE EUGENIA BURKARTIANA (D. LEGRAND) D. LEGRAND E MYRCIARIA CUSPIDATA O. BERG, DUAS MIRTOÍDEAS NATIVAS NO RIO GRANDE DO SUL ${ }^{1}$
}

\author{
SIDINEI RODRIGUES DOS SANTOS² JOSÉ NEWTON CARDOSO MARCHIORI ${ }^{3}$
}

\begin{abstract}
RESUMO
No presente estudo são descritos e ilustrados os caracteres anatômicos do lenho de Eugenia burkartiana D. Legrand (D. Legrand) e Myrciaria cuspidata O. Berg, a partir de material coletado no Rio Grande do Sul. As características anatômicas em comum corroboram a conhecida homogeneidade estrutural das Myrtaceae. Entre os caracteres anatômicos diferenciais, salientam-se o arranjo do parênquima axial, a presença e/ou abundância de conteúdos nos raios e de séries cristalíferas no parênquima axial, bem como a composição celular nas margens de raios e a freqüência de poros.

Palavras-chave: Eugenia burkartiana, Myrciaria cuspidata, anatomia da madeira, Myrtaceae.
\end{abstract}

\section{ABSTRACT}

[Wood anatomy of Eugenia burkartiana (D. Legrand) D. Legrand and Myrciaria cuspidata O. Berg, two native Myrtoideae from Rio Grande do Sul state, Brazil].

The wood anatomy of Eugenia burkartiana (D. Legrand) D. Legrand and Myrciaria cuspidata O. Berg are described and illustrated, based on samples from Rio Grande do Sul state, Brazil. The anatomical features shared by the two species reinforce the well known structural homogeneity of Myrtaceae family. To segregate both species are specially important: the arrangement of axial parenchyma; the presence and/or abundance of organic inclusions in rays; the presence of crystalliferous strands on axial parenchyma; the cellular composition of ray margins (uniseriate ends); and the frequency of pores.

Key words: Eugenia burkartiana, Myrciaria cuspidata, wood anatomy, Myrtaceae.

\section{INTRODUÇÃO}

As Myrtaceae compreendem um amplo conjunto de plantas, integrantes de distintas formações vegetacionais. No Brasil, são referidas em torno de 1000 espécies de árvores e arbustos, todas pertencentes à subfamília Myrtoideae ou tribo Myrteae. Chama atenção a complexidade taxonômica da família, resultante não apenas do

1 Recebido para publicação em 4-IV-2010 e aceito para publicação em 6-V-2010.

2 Biólogo, bolsista (CNPq-Brasil), doutorando do Programa de Pós-Graduação em Engenharia Florestal, Departamento de Ciências Florestais, Universidade Federal de Santa Maria. CEP 97105-900. Santa Maria, RS, Brasil.sthurt.bio@gmail.com

3 Engenheiro Florestal, Dr., bolsista de Produtividade em Pesquisa (CNPq - Brasil), Professor Titular do Departamento de Ciências Florestais, Universidade Federal de Santa Maria. Santa Maria, RS, Brasil. balduinia@mail.ufsm.br elevado número de espécies, mas, sobretudo, da semelhança morfológica entre os diferentes taxa e da adoção de caracteres considerados críticos para a delimitação das mesmas (Landrum \& Kawasaki, 1997), fato que justifica e recomenda a realização de estudos em diversas áreas, incluindo a anatomia da madeira, com vistas ao melhor esclarecimento destas questões.

O presente estudo, ao descrever a estrutura microscópica do lenho de Eugenia burkartiana (D. Legrand) D. Legrand e Myrciaria cuspidata $\mathrm{O}$. Berg, dá continuidade à serie de publicações sobre a anatomia de Myrtaceae nativas no Rio Grande do Sul, visando a contribuir ao conhecimento estrutural da família.

Restrita ao Alto Uruguai (Sobral, 2003), Eugenia bukartiana (D. Legrand) D. Legrand é arvoreta de $2-5 \mathrm{~m}$ de altura, e córtex rugoso, nativa na Argentina, Paraguai e Brasil, do Paraná 
ao Rio Grande do Sul (Legrand \& Klein, 1969). Dos caracteres importantes para a identificação, salientam-se as flores sésseis e as folhas discolores, cujas nervuras se distanciam mais de $3 \mathrm{~mm}$ da borda (Sobral, 2003). A espécie recebe o nome popular de guamirim e sua madeira, desconhecida anatomicamente, carece de interesse comercial.

Myrciaria cuspidata $\mathrm{O}$. Berg é arbusto ou árvore pequena, com até $7 \mathrm{~m}$ de altura e $25 \mathrm{~cm}$ de D. A. P. (Marchiori \& Sobral 1997), reconhecida pelo córtex liso, exfoliante, e pelas folhas glabras, estreitas (geralmente menores de $10 \mathrm{~mm}$ ), tipicamente mucronadas no ápice (Sobral, 2003). Conhecida localmente como camboim, produz madeira avermelhada e de alto poder calorífico, cuja estrutura anatômica segue desconhecida. Myrciaria cuspidata é nativa na Bolívia, Paraguai e Brasil, do Ceará ao Rio Grande do Sul. Neste Estado, pode ser encontrada na Floresta Estacional da Depressão Central, bem como nas florestas e campos rupestres da Serra do Sudeste e na Restinga litorânea (Sobral, 2003).

\section{REVISÃO DE LITERATURA}

É ainda incipiente o conhecimento anatômico dos representantes sul-rio-grandenses da família Myrtaceae, não ultrapassando a trinta, num total de 109 (Sobral, 2003), o número de espécies descritas até o momento. Merece destaque, neste contexto, as contribuições de Marchiori (1984a,b,c; 1987; 1988; 1998), Marchiori \& Muniz (1987), Marchiori \& Brum (1997), Marchiori et al. (2008), Denardi \& Marchiori (2005a,b) e Denardi et al. (2005).

Em estudo de Eugenia involucrata DC., Marchiori (1984a) refere, entre outros aspectos: porosidade difusa; poros numerosos a muito numerosos $\left(20 / \mathrm{mm}^{2}\right)$; placas de perfuração simples; raios heterogêneos; e traqueídeos vasicêntricos. Para a identificação da espécie, destaca-se a presença de tênues espessamentos espiralados em vasos, de pontoações simples em fibras, bem como a ocorrência de séries cristalíferas no parênquima axial. Para os repre- sentantes brasileiros do gênero, constam, ainda, na literatura, os trabalhos de Barros \& Callado (1997), Soffiatti \& Angyalossy-Alfonso (1999), Barros et al. (2001; 2003) e Marques et al. (2007).

Para a madeira de Myrciaria tenella, Marchiori \& Muñiz (1987) relacionam os seguintes aspectos anatômicos: poros solitários, extremamente numerosos $\left(177 / \mathrm{mm}^{2}\right)$ e pequenos $(29 \mu \mathrm{m})$; placas de perfuração simples; pontoações intervasculares alternas, ornamentadas; parênquima apotraqueal difuso e subagregado, em séries de 3 - 7 células; raios heterogêneos, com 1 - 3 células de largura; e fibras de paredes espessas, com pontoações areoladas. Das características referidas, salientam-se a porosidade semi-difusa, bem como a ausência de espessamentos espiralados e cristais. Sobre as demais espécies brasileiras do gênero, não constam referências na literatura consultada, nem mesmo nas obras clássicas de Record \& Hess (1949) e Metcalfe \& Chalk (1972).

\section{MATERIAL E MÉTODOS}

O material estudado consiste de duas amostras de madeira e respectivas exsicatas botânicas, incorporadas à Xiloteca e Herbário do Departamento de Ciências Florestais (HDCF) da Universidade Federal de Santa Maria, com os seguintes registros:

- HDCF 2812, Eugenia burkartiana, Tenente Portela, RS. Marchiori n.432, 8-VIII-1986.

- HDCF 2275, Myrciaria cuspidata, Jaguari, RS. Marchiori n. 323, 17-I-1986.

A confecção de lâminas histológicas e de macerado seguiu a técnica padrão (Burger \& Richter, 1991). Para o tingimento dos cortes anatômicos, usou-se tripla-coloração, com acridina-vermelha, crisoidina e azul-de-astra; para o macerado, apenas safranina (1\%).

A descrição baseou-se nas recomendações do IAWA Committee (1989). As medições foram realizadas em microscópio Carl Zeiss, no Laboratório de Anatomia da Madeira da Universidade Federal de Santa Maria. Nas características quantitativas, os números entre parên- 
teses equivalem aos valores mínimos e máximos observados; o valor que acompanha a média é o desvio padrão. As fotomicrografias foram tomadas em microscópio Olympus CX40, equipado com câmera digital Olympus Camedia c3000, no Laboratório de Anatomia da Madeira da Universidade Federal do Paraná, a quem os autores agradecem.

\section{DESCRIÇÕES ANATÔMICAS}

\section{Eugenia burkartiana}

Anéis de crescimento: distintos, delimitados, fracamente, por fina camada de fibras radialmente estreitas (Figura 1A).

Vasos: numerosos a muito numerosos $(46 \pm$ $15(25-62)$ poros $\left./ \mathrm{mm}^{2}\right)$, ocupando $4 \pm 1,5 \%$ do volume da madeira. Porosidade difusa (Figura 1A). Poros exclusivamente solitários, poligonais, muito pequenos $(24,6 \pm 7,4(12,5-$ $37,5) \mu \mathrm{m})$, de paredes finas $(2,5 \pm 0,6(1,2-$ $3,7) \mu \mathrm{m})$ e sem padrão definido de organização (Figura 1A,B). Elementos vasculares de comprimento médio $(565 \pm 103,2(390-760 \mu \mathrm{m})$, com placas de perfuração simples, geralmente oblíquas, e apêndices em ambas as extremidades. Pontoações intervasculares alternas, circulares $(4,7 \pm 0,53(4,1-5,1) \mu \mathrm{m})$, com abertura em fenda inclusa, ornamentada. Pontoações raio-vasculares com aréolas distintas, semelhantes às intervasculares, porém menores $(3,7 \pm$ $0,53(3,1-4,1) \mu \mathrm{m})$ e restritas às margens de raios. Espessamentos espiralados e conteúdos, ausentes.

Parênquima axial: muito distinto das fibras em corte transversal, representando $15,3 \pm 3,7 \%$ do volume da madeira; em arranjo apotraqueal difuso e, principalmente, difuso-em-agregados, com tendência a formar faixas tangenciais irregulares de $1-4$ células de largura, mais ou menos contínuas; parênquima paratraqueal escasso, pouco frequente (Figura 1A,B). Séries parenquimáticas com 4 - 8 (9) células, medindo $547 \pm 104(327-713) \mu \mathrm{m}$ de altura (Figura $1 \mathrm{E})$. Cristais prismáticos em séries de até 8 unidades, em câmaras distendidas do parênquima axial (Figura 1F).
Raios: muito numerosos $(26 \pm 1,7$ (22 - 28) raios/mm), com $1-2$ células de largura (Figura $1 F)$, ocupando $19,8 \pm 4,2 \%$ do volume da madeira. Raios multisseriados com $376 \pm 184(150$ - 760) $\mu \mathrm{m}$ e $6-26$, mais comumente $9-20$ células de altura; heterogêneos, reúnem células procumbentes, na parte multisseriada, e (1) 3 5 (12) fileiras marginais de células quadradas e principalmente eretas, raro procumbentes mais altas do que as do corpo central (Figura 1C). A parte multisseriada é geralmente mais curta do que as margens unisseriadas (Figura 1E,F). Os unisseriados, com $216 \pm 143(60-660) \mu \mathrm{m}$ e 1 - 5 (15) células de altura. Raios axialmente fusionados, frequentes. Células radiais de paredes disjuntas, presentes (Figura 1D). Inclusões minerais, células envolventes e células perfuradas, ausentes. Conteúdo de cor escura ou avermelhada, escasso.

Fibras: com pontoações areoladas e aberturas cruzadas, presentes nas faces radiais e tangenciais da parede. Tecido fibroso representando $60,8 \pm 4,7 \%$ do volume da madeira. Fibras de comprimento médio $(1077 \pm 185$ (700 1420) $\mu \mathrm{m})$, com $13,6 \pm 1,8(10-17,5) \mu \mathrm{m}$ de largura e de paredes muito espessas $(4,4 \pm 0,7$ $(3,1-5,6) \mu \mathrm{m})$ (Figura 1B). Fibras septadas, fibras gelatinosas e espessamentos espiralados, ausentes. Traqueídeos vasicêntricos, presentes.

Outros caracteres: variantes cambiais, tubos laticíferos e taniníferos, canais intercelulares, células oleíferas ou mucilaginosas, máculas medulares e estratificação, ausentes.

\section{Myrciaria cuspidata}

Anéis de crescimento: pouco distintos, delimitados, fracamente, por fina camada de fibras radialmente estreitas (Figura 2B).

Vasos: muito numerosos a extremamente numerosos $\left(131 \pm 42(81-181)\right.$ poros $\left./ \mathrm{mm}^{2}\right)$, ocupando $12,5 \pm 2,2 \%$ do volume da madeira. Porosidade difusa (Figura 2A). Poros exclusivamente solitários, ligeiramente poligonais, muito pequenos $(29 \pm 6,6(15-40) \mu \mathrm{m})$, de paredes finas $(2,9 \pm 0,4(2-4) \mu \mathrm{m})$ e sem padrão definido de organização (Figura 2A,B). 

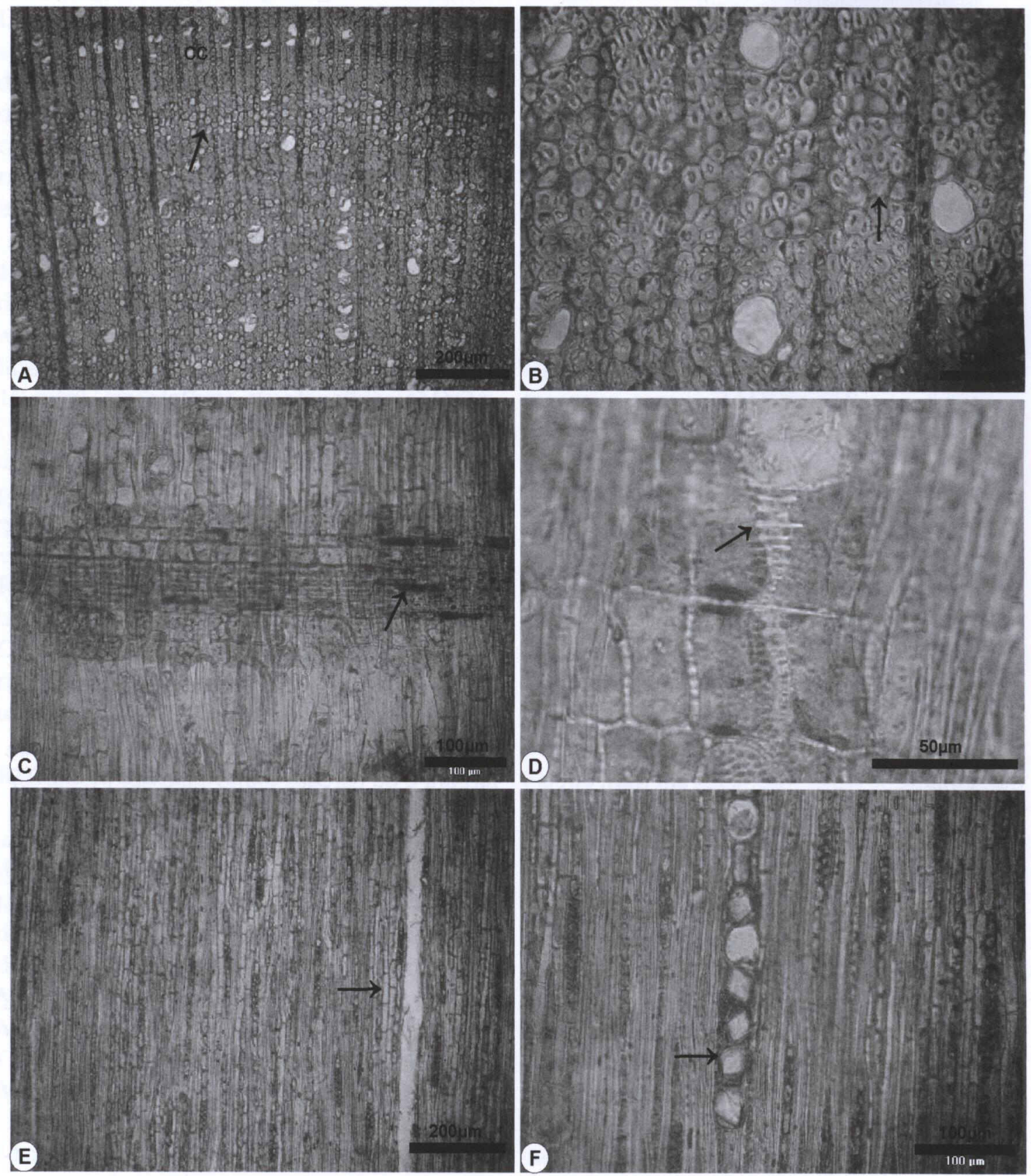

FIGURA 1 - Fotomicrografias da madeira de Eugenia burkartiana. A - Seção transversal, mostrando porosidade difusa, poros exclusivamente solitários, parênquima apotraqueal difuso-em-agregados e em faixas tangenciais (seta), e limite de anel de crescimento (cc). B - Mesma seção, em maior aumento, destacando vasos de seção poligonal, fibras de paredes muito espessas e parênquima apotraqueal difuso-em-agregados (seta). C - Raio heterogêneo, com corpo central de células procumbentes e escasso conteúdo (seta), em seção longitudinal radial. D - Raio com células de paredes disjuntas (seta), em seção longitudinal radial. E - Aspecto geral da seção longitudinal tangencial, com destaque para raios estreitos e parênquima seriado (seta). F - Mesmo plano anatômico, com maior aumento, destacando raios uni e bisseriados e cristais em câmaras distendidas no parênquima axial (seta). 
Elementos vasculares de comprimento médio $(439 \pm 92(270-620 \mu \mathrm{m})$, com placas de perfuração simples (Figura 2D), geralmente oblíquas e com apêndices geralmente em ambas as extremidades. Pontoações intervasculares alternas, circulares $(3,8 \pm 0,7(3-5) \mu \mathrm{m})$, com abertura em fenda inclusa, não ornamentada (Figura 2F). Pontoações raio-vasculares com aréolas distintas, semelhantes às intervasculares, porém menores $(2,4 \pm 0,5(2-3) \mu \mathrm{m})$ e restritas às margens de raios. Espessamentos espiralados, ausentes. Conteúdo avermelhado, escasso.

Parênquima axial: muito distinto das fibras em corte transversal, representando $12,8 \pm 4,3 \%$ do volume da madeira; em arranjos apotraqueal difuso e difuso-em-agregados, além de paratraqueal escasso (Figura 2A, B). Séries parenquimáticas geralmente com $4-7(3-8)$ células, e $407 \pm 64(200-515) \mu \mathrm{m}$ de altura (Figura 2E).

Raios: muito numerosos $(29 \pm 1,9(26-32)$ raios $/ \mathrm{mm}$ ), com $1-2$, raro 3 células de largura (Figura 2E, F), ocupando $20 \pm 2,3 \%$ do volume da madeira. Raios multisseriados com $302 \pm 125$ $(140-700) \mu \mathrm{m}$ e $7-25$, mais comumente 12 14 células de altura; heterogêneos, reúnem células procumbentes, na parte multisseriada, e 2 - 6 (17) fileiras marginais de células quadradas, eretas e, menos comumente, procumbentes mais altas do que as do corpo central (Figura 2C). A parte multisseriada é geralmente mais curta do que as margens unisseriadas (Figura 2E, F). Os unisseriados, com $176 \pm 87$ (50 460) $\mu \mathrm{m}$ e $1-12$, mais comumente 2 - 5 células de altura. Raios axialmente fusionados, frequentes. Células radiais de paredes disjuntas, presentes. Células envolventes e células perfuradas, ausentes. Conteúdo avermelhado, muito abundante (Figura 2C, D).

Fibras: com pontoações areoladas e aberturas geralmente cruzadas, presentes nas faces radiais e tangenciais da parede. Tecido fibroso representando $54,7 \pm 3,6 \%$ do volume da madeira. Fibras de comprimento médio (937 \pm 134 $(650-1190) \mu \mathrm{m})$, com $13 \pm 2(10-17,5) \mu \mathrm{m}$ de largura e de paredes finas, espessas até mui- to espessas $(4,7 \pm 0,7(3,5-6) \mu \mathrm{m})$ (Figura 2B). Fibras septadas, fibras gelatinosas e espessamentos espiralados, ausentes. Traqueídeos vasicêntricos, presentes.

Outros caracteres: Variantes cambiais, tubos laticíferos e taniníferos, canais intercelulares, células oleíferas ou mucilaginosas, estratificação e cristais, ausentes. Máculas medulares, ocasionais, com canais traumáticos e cristais associados.

\section{ANÁLISE DA ESTRUTURA ANATÔMICA}

Estruturalmente semelhantes, Eugenia burkartiana e Myrciaria cuspidata apresentam diversas características anatômicas em comum, em consonância com a conhecida homogeneidade estrutural das Myrtaceae. É o caso, por exemplo: da porosidade difusa; dos poros solitários; dos elementos vasculares de comprimento médio; das placas de perfuração simples; das pontoações intervasculares alternas; da ausência de espessamentos espiralados; da presença de traqueídeos vasicêntricos; do parênquima axial seriado; dos raios heterogêneos, estreitos; e das fibras de comprimento médio, com pontoações areoladas na parede. Este conjunto de características está de acordo com as possibilidades estruturais das Mirtoídeas nativas (Marchiori, 1984a,b,c; 1987; 1988; 1998; Marchiori \& Muniz, 1987; Marchiori \& Brum, 1997; Marchiori et al., 2008; Denardi \& Marchiori, 2005a,b; Denardi et al., 2005), bem como com o referido para a família, por Record \& Hess (1949), Metcalfe \& Chalk (1972) e Vliet \& Baas (1984).

Confirmando o valor do parênquima axial na taxonomia da família, foram observadas diferenças significativas no arranjo do referido caráter anatômico entre as duas espécies investigadas: em Eugenia burkartiana, o parênquima axial tende a formar faixas tangenciais, aspecto não observado em $M y r-$ ciaria cuspidata, que tem apenas parênquima difuso e difuso-em-agregados.

Das características diferenciais, merecem destaque, além do parênquima axial, a ocorrên- 

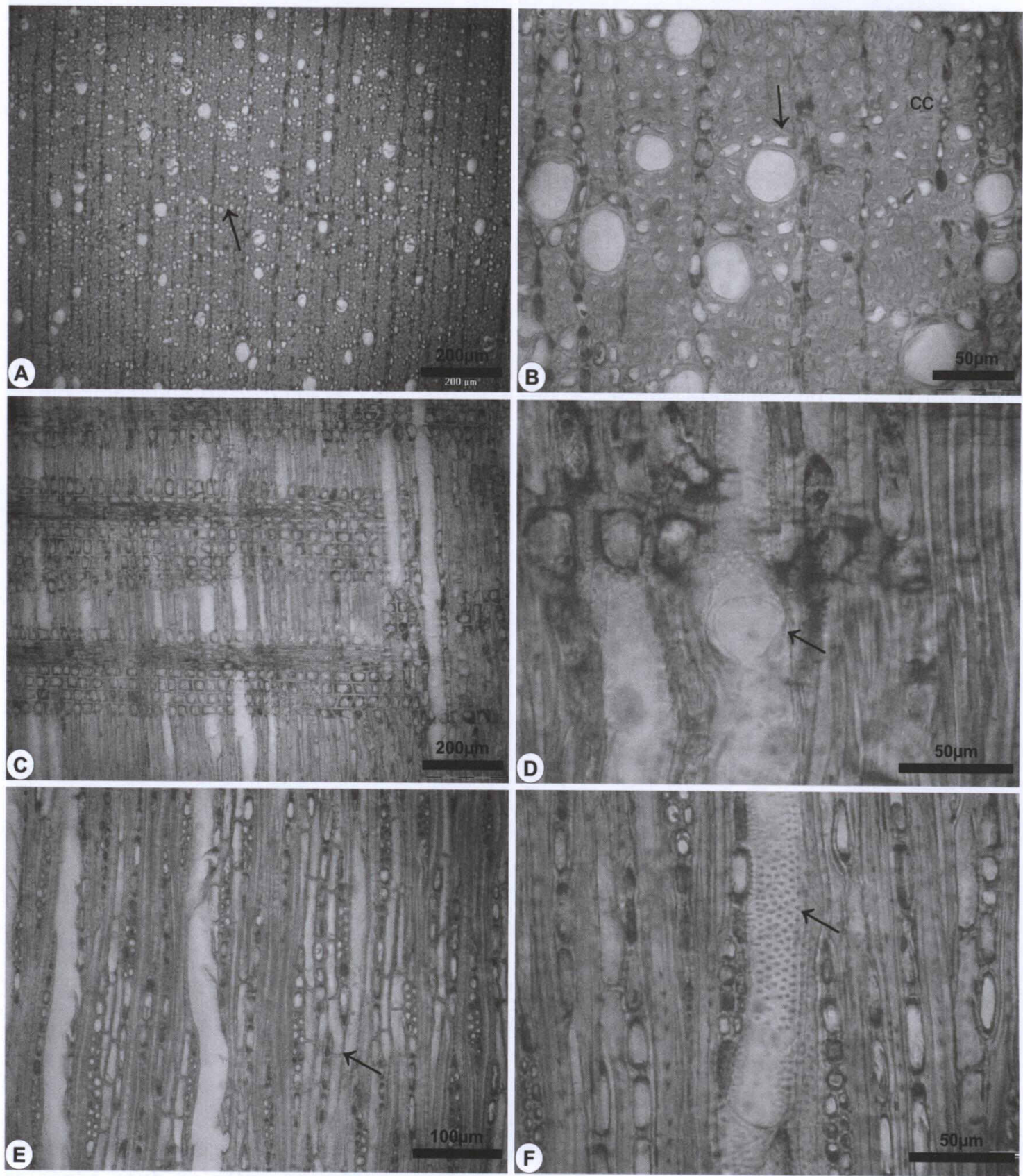

FIGURA 2 - Fotomicrografias da madeira de Myrciaria cuspidata. A - Seção transversal, mostrando porosidade difusa, poros exclusivamente solitários e parênquima apotraqueal difuso e difuso-em-agregados (seta). B - Mesmo plano anatômico, em maior aumento, destacando vasos ligeiramente poligonais, parênquima apotraqueal difuso-em-agregados (seta), fibras de paredes finas, espessas até muito espessas, e limite de anel de crescimento (cc). C - Raio heterogêneo, com corpo central de células procumbentes e margens de células quadradas e eretas, com abundante conteúdo (seção longitudinal radial). D - Mesmo plano anatômico da foto anterior, destacando uma placa de perfuração simples (seta). E - Série de parênquima (seta), raios e vasos, em seção longitudinal tangencial. F - Mesma seção, em maior aumento, mostrando raios uni e bisseriados e pontoações intervasculares alternas (seta). 
cia de séries cristalíferas e a presença de conteúdos. Em Eugenia burkartiana são observados cristais prismáticos em câmaras distendidas no parênquima axial, e o conteúdo em células de raios é ausente ou escasso; Myrciaria cuspidata, por sua vez, apresenta abundante conteúdo no tecido radial, mas não tem cristais. Tanto cristais como conteúdos são ausentes em Myrciaria tenella, pesquisada por Marchiori \& Muñiz (1987). Séries cristalíferas, todavia, são referidas no parênquima axial de Eugenia involucrata (Marchiori, 1984a).

Outro aspecto que pode auxiliar na separação das espécies é a composição do tecido radial, mais especificamente de suas margens: em Eugenia burkartiana predominam células eretas, enquanto que em Myrciaria cuspidata verifica-se uma mistura de células quadradas e eretas, em proporções semelhantes.

No tocante às características quantitativas, destaca-se apenas a freqüência de poros, posto que em Myrciaria cuspidata (131 poros $/ \mathrm{mm}^{2}$ ) o caráter é significativamente maior do que o observado em Eugenia burkartiana (46 poros/ $\mathrm{mm}^{2}$ ). Na comparação desta espécie com Eugenia involucrata, salientam-se diferenças no tocante ao diâmetro de poros, bem como na frequiência de vasos e raios. Myrciaria cuspidata e Myrciaria tenella, por outro lado, não apresentam diferenças suficientemente importantes a serem ressaltadas.

Tendo por base o referido para outras espécies brasileiras de Eugenia na literatura (Barros \& Callado, 1997; Soffiatti \& AngyalossyAlfonso, 1999; Barros et al., 2001; 2003; Marques et al., 2007), pode-se destacar, como aspectos de maior utilidade para a taxonomia do gênero, o arranjo do parênquima axial e a presença ou não de cristais. Menos variável, o arranjo de poros, assim como certas características quantitativas (freqüência e diâmetro de poros, comprimento de elementos vasculares e de fibras, e altura e frequiência de raios), podem ter eventual utilidade. Cabe lembrar, todavia, que características quantitativas, em especial de vasos, são muito influenciadas pelas condições ambientais, devendo, portanto, serem tomadas com cautela.

Resta comentar sobre as diferenças no tocante à porosidade em Myrciaria cuspidata . Pouco freqüente na família, a porosidade semidifusa é referida para Myrciaria tenella; Myrciaria cuspidata, todavia, apresenta porosidade difusa. Como no caso das características quantitativas, a distribuição de poros pode ser influenciada pelas condições do meio, fato que limita sua utilização para fins taxonômicos.

\section{REFERÊNCIAS BIBLIOGRÁFICAS}

BARROS, C.F.; CALLADO, C.H. Madeiras da mata atlântica. Anatomia do lenho de espécies ocorrentes nos remanescentes florestais do estado do Rio de Janeiro, Brasil. Rio de Janeiro: Instituto de Pesquisas Jardim Botânico do Rio de Janeiro. 1997. v. 1.86 p.

BARROS, C.F.; CALLADO, C.H.; MARCON, M.L.; COSTA, C.G.; CUNHA, M.; LIMA, H.R.P.; MARQUETE, O. Madeiras da Mata Atlântica. Anatomia do lenho de espécies ocorrentes nos remanescentes florestais do estado do Rio de Janeiro, Brasil. Rio de Janeiro: Instituto de Pesquisas Jardim Botânico do Rio de Janeiro. 2001. 94p.

BARROS, C.F.; CALLADO, C.H.; CUNHA, M.; MARCON, M.L.F.; TAMAIO, N.; MARQUETE, O.; COSTA, C.G. Madeiras da Mata Atlântica. Anatomia do lenho de espécies ocorrentes nos remanescentes florestais do estado do Rio de Janeiro, Brasil. Rio de Janeiro: Instituto de Pesquisas Jardim Botânico do Rio de Janeiro. 2003. 86p.

BURGER, L.M.; RICHTER, H.G. Anatomia da Madeira. São Paulo: Ed. Nobel, 1991. 154 p.

DENARDI, L.; MARCHIORI, J.N.C. Anatomia ecológica da madeira de Blepharocalyx salicifolius (H.B.K.) Berg. Ciência Florestal, Santa Maria, v. 15 , n. 2, p. 119-127, 2005 a.

DENARDI, L.; MARCHIORI, J.N.C. Anatomia do lenho da murta, Blepharocalyx salicifolius $(\mathrm{H}$. B. K.) Berg. Ciência Florestal, Santa Maria, v. 15, n. 3 , p. $267-274,2005$ b. 
DENARDI, L.; MARCHIORI, J.N.C.; FERREIRA, M.R. Anatomia da madeira de Plinia rivularis (Camb.) Rotman. Balduinia, Santa Maria, n. 3, p. 21-25, 2005.

IAWA COMMITTEE. IAWA list of microscopic features for hardwood identification. IAWA Bulletin, v. 10, n. 3, p. 218-359, 1989.

LANDRUM, L.R.; KAWASAKI, M.L. The genera of Myrtaceae in Brasil: an illustrated synoptic treatment and identification keys. Brittonia, n. 49, p. 508-536, 1997.

LEGRAND, D.; KLEIN, R.M. Mirtáceas. 2. Eugenia L. In: REITZ, P.R. Flora Ilustrada Catarinense. Itajaí: Herbário Barbosa Rodrigues, 1969. p. 45216.

MARCHIORI, J.N.C. Anatomia da madeira de Eugenia involucrata DC. (Myrtaceae). Ciência e Natura, Santa Maria, v. 6, p. 127-136, 1984a.

MARCHIORI, J.N.C. Anatomia descritiva da madeira do murtilho Myrrhinium loranthoides (Hook. \& Arn.) Burret (Myrtaceae). Revista do Centro de Ciências Rurais, Santa Maria, v. 14, n. 1, p. 43-50, 1984b.

MARCHIORI, J.N.C. Anatomia descritiva do lenho de Feijoa sellowiana Berg. Ciência e Natura, Santa Maria, v. 6, p. 117-125, 1984c.

MARCHIORI, J.N.C. Anatomia descritiva da madeira de Myrceugenia myrtoides Berg. Ciência e Natura, Santa Maria, v. 9, p. 113-120, 1987.

MARCHIORI, J.N.C. Estudo anatômico da madeira de Myrceugenia glaucescens (Camb.) Legr. et Kaus. Ciência e Natura, Santa Maria, v. 10, p. 105-113, 1988.

MARCHIORI, J.N.C. Estudo anatômico da madeira de sete-capotes, Campomanesia guazumifolia (Camb.) Berg. (Myrtaceae). Ciência Rural, Santa Maria, v. 28, n. 1, p. 47-51, 1998.
MARCHIORI, J.N.C, BRUM, E.T. Anatomia da madeira do guamirim-facho, Calyptranthes concinna DC. (Myrtaceae). Ciência Rural, Santa Maria, v. 27, n. 2, p. 217-222, 1997.

MARCHIORI, J.N.C.; DENARDI, L.; FERREIRA, M.R. Anatomia da madeira de Myrcianthes gigantea (Legr.) Legr. Balduinia, Santa Maria, n. 12, p. 27-31, 2008.

MARCHIORI, J.N.C.; MUÑIZ, G.I.B. Estudo anatômico da madeira de Myrciaria tenella (DC.) Berg. Ciência e Natura, Santa Maria, v. 9, p. 87-95, 1987.

MARCHIORI, J.N.C.; SOBRAL, M. Dendrologia das Angiospermas: Myrtales. Santa Maria: Editora UFSM, 1997. 304 p.

MARQUES, P.A.; ARAUJO, G.U.C.; BARROS, C.F.; CALLADO, C.H. Anatomia do lenho de três espécies de Eugenia L. (Myrtaceae) de mata e restinga. Revista Brasileira de Biociências, v. 5, p. 801-803, 2007.

METCALFE, C.R.; CHALK, L. Anatomy of the Dicotyledons. Oxford: Clarendon Press, 1972. $1500 \mathrm{p}$.

RECORD, S.J.; HESS R.W. Timbers of the New World. New Haven: Yale University Press, 1949. $640 \mathrm{p}$.

SOBRAL, M. A família Myrtaceae no Rio Grande do Sul. São Leopoldo: Editora Unisinos, 2003. $216 \mathrm{p}$.

SOFFIATTI, P.; ANGYALOSSY-ALFONSO, V. Estudo anatômico comparativo do lenho e da casca de duas espécies de Eugenia L. (Myrtaceae). Revista Brasileira de Botânica, São Paulo, v. 22, n. 2, p. 175-184, 1999.

VLIET, G.J.C. van; BAAS, P. Wood anatomy and classification of the Myrtales. Annals of the Missouri Botanical Garden, n. 71, p. 783-800, 1984. 